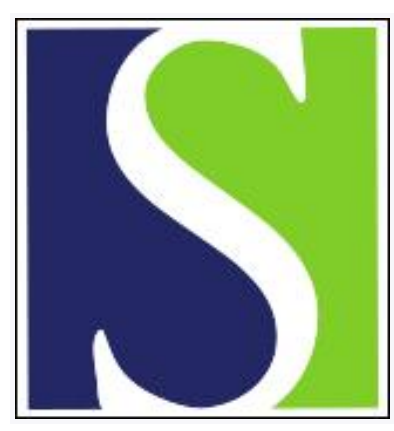

Scand J Work Environ Health 1982;8(2):134-136

https://doi.org/10.5271/sjweh.2490

Issue date: Jun 1982

\title{
Classification of low-back pain.
}

by Nachemson AL, Andersson GB

Key terms: back; back pain; classification; epidemiology; low-back insufficiency; low-back pain; lumbago; pain; sciatica; short communication

This article in PubMed: www.ncbi.nlm.nih.gov/pubmed/6215709

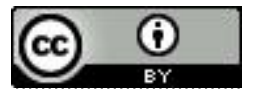




\title{
Classification of low-back pain
}

\author{
by Alf L Nachemson, MD, Gunnar BJ Andersson, MD'
}

\begin{abstract}
NACHEMSON AL, ANDERSSON GBJ. Classification of low-back pain. Scand $j$ work environ health 8 (1982) 134-136. A system of classifying low-back disorders is presented that is suitable for use in epidemiologic screening. It is based on the patient's description of symptoms and can be verified by simple clinical findings. The duration and onset of the disease is given as a prefix, and additional information is included as parenthetical data.
\end{abstract}

Key terms: epidemiology, low-back insufficiency, lumbago, sciatica.

Before knowledge of the epidemiology of low-back disorders can be increased and different types of treatment can be evaluated, it is imperative that a uniform system of classification be developed. Currently there is no standard system of evaluation nor general agreement on the definition of basic terminology. In the International Classification of Diseases, Adapted (7), the terminology most commonly used in the indexing of hospital records and morbidity statistics, number 728.70 is assigned to lumbalgia, 717.00 to lumbago, and 728.90 to unspecified back pain. Sciatica (353.99) is not mentioned among diseases of the musculoskeletal system at all but, instead, is listed under the heading of "diseases in peripheral nerves and sensory organs." Syndroma radicularis extremitatum inferiorum (728.80), on the other hand, is found among diseases of the musculoskeletal system, as is also dislocatio disci intervertebralis lumbalis (725.10). A patient with a classical history and findings of true disc prolaps can thus be classified alternatively under the numbers 725.10, 353.99 and 728.80 .

Certainly, one reason for this confusing picture is that the exact etiology of the pain remains unknown for the majority of patients. In addition to a lack of under1 Department of Orthopaedic Surgery I, Sahl-
gren Hospital, Göteborg, Sweden.

Reprint requests to: Dr GBJ Andersson, Department of Orthopaedic Surgery, Sahlgren Hospital, S-413 45 Göteborg, Sweden. standing of the fundamental pathophysiology of lumbar spine diseases, research efforts are retarded by a lack of agreement on a universally acceptable language with which to express ideas and compare results.

Orthopedic surgeons, neurosurgeons, neurologists, rheumatologists, and others frequently use different terminology and base their diagnosis and treatment on different "pathology." An examination of the literature however shows that the terminology and principles of classifications differ even within each specialty. We would like to introduce a simple terminology system as a first step toward standardizing the evaluation of lumbar spine diseases.

\section{Suggestion}

Our proposed system of classification relates terminology to symptoms. All definitions are based on the patient's own description. Each such symptom-related diagnosis can be verified by simple clinical findings. The duration and onset of the disease is given as a prefix. In parentheses, after the symptom diagnosis, additional information can be included, as, for example, radiographic results. Our suggestion is presented in the appendix. Used as examples in the appendix are acute lumbago (traumatica), chronic lumbago (degeneratio disci intervertebralis lumbalis), and recurring insuffientia dorsi (lumbar osteochondrosis). 


\section{Discussion}

When a simple system like the one suggested is introduced, its use should of course be considered. Our main purpose is to achieve a uniform classification that simplifies the recording of the incidence and prevalence of low-back disorders in the society as a whole. Only then can meaningful epidemiologic data be collected. In studies in which particular details are of interest, the system can easily be broadened to include additional information of interest.

The prefixes "acute" and "subacute" differ with respect to the onset of the pain, while acute and chronic differ with respect to the duration of the symptoms. Three months was chosen because $90 \%$ of the patients with back pain recover within that period (8).

The symptom diagnosis should be based on the patient's symptoms alone, and the findings used only as supporting evidence. The text describing each symptom diagnosis in the appendix is meant as an explanation of the term and not as an exact definition. A patient may, for instance, be completely without objective findings and still receive the diagnosis insufficientia dorsi.

Radiographic diagnoses, social diagnoses, etc, have not been defined, as they are already classified. Because of the present poor knowledge of the etiology of back pain, it is seldom possible to use radiographic diagnoses alone as a clinical classification. Even though tumors, spondylitis, and other diseases can be verified radiographically, it is usually the clinical state of the patient that is the reason for the investigation. Many commonly used radiographic diagnoses lack clinical importance and are as frequently seen in subjects without as in those with back pain. We therefore suggest, until evidence is available, that the information obtained from radiographs, as well as other useful information from other sources, be given in parentheses after the symptom diagnosis.

The system of classification suggested in the present report is a modification of that used by several Swedish investigators in the past $(2,3,4,5,6,10)$. It has been used in the present form by Bergqvist-Ullman
\& Larsson (1) and Svensson \& Andersson (9). It is simple to use and differentiates well between diagnoses, and the diagnostic groups differ with respect to severity of symptoms and course of recovery (Andersson et al, unpublished results). No specific diagnostic tests are required, although a clinical examination is helpful; therefore the system is useful for screening purposes.

\section{Acknowledgment}

The present study was supported by a grant from the Swedish Work Environment Fund.

\section{References}

1. Bergqvist-Ullman M, Larsson U. Acute low back pain in industry. Acta orthop scand suppl 170 (1977) $117 \mathrm{p}$.

2. Dehlin O, Hedenrud B, Horal J. Back symptoms in nursing aides in a geriatric hospital. Scand j rehabil med 8 (1976) $47-53$.

3. Hirsch C, Jonsson B, Lewin T. Low back symptoms in a Swedish female population. Clin ortop 63 (1969) $171-176$.

4. Horal J. The clinical appearance of low back pain disorders in the city of Gothenburg, Sweden: Comparisons of incapacitated probands with matched controls. Acta orthop scand suppl 188 (1969) 76 p.

5. Hult L. Cervical dorsal and lumbar spinal syndromes. Acta orthop scand suppl 17 (1954) $102 \mathrm{p}$.

6. Hult L. The Munkfors investigation. Acta orthop scand suppl 16 (1954).

7. National Center for Health Statistics. International classification of diseases, adapted. US Department of Health, Education and Welfare, Public Health Service, Washington, DC 1968.

8. Svensson $\mathrm{H}-\mathrm{O}$. Low back pain in $40-47$ year old men. University of Göteborg, Göteborg 1981. (Doctoral thesis).

9. Svensson H-O, Andersson GBJ. Low back pain in 40-47 year old men: Frequency of occurrence and impact on medical services. Scand j rehabil med (in press).

10. Westrin C-G. Low back sick-listing: A nosological and medical insurance investigation. Scand j soc med (1970): suppl 7, $102 \mathrm{p}$.

\section{Appendix}

Proposed system of classification for low-back disorders

\section{Prefix}

Acute: $0-3$ months in duration; immediate onset. 
Subacute: $0-3$ months in duration: slow onset.

Chronic: more than 3 months in duration.

Recurring: symptoms recurring after an interval of no symptoms.

\section{Symptom diagnosis}

Insufficientia dorsi. Tiredness, discomfort, or pain is provoked by repeated or forceful movements. The symptoms are localized in the lumbar region. The back feels stiff or weak.

Lumbago. Ache and pain that are localized in the lumbar region and sometimes radiate down over the gluteal region, the hip region, or the inguinal region. The symptoms are increased in the acute stages by all movements. In the more chronic stages they are increased only by certain movements and stresses which particularly include the lumbar spine. The symptoms may begin acutely or gradually.

Sciatica. a. Sciatica: Ache and radiating pain occur in one or both legs. The symptoms are increased in the acute stages by all movements, and in the more chronic stages only by certain movements. The symptoms can either occur instantaneously or increase rapidly over a short period. The clinical picture often includes numbness, paresthesia, and a feeling of weakness in one or both legs.

b. Rhizopathy: A special form of sciatica characterized by radiation to the leg in a segmental distribution. Patients may or may not have neurological disturbances which can be attributed to the affected segment.

Lumbago sciatica. Symptoms occur as for both lumbago and sciatica. One of the two can dominate.

\section{Clinical findings}

Insufficientia dorsi. There is more rarely pain on palpation of the lumbar spine. No increase in muscular tension occurs. There is no or only a slight increase in pain during motion of the lumbar spine. No neu- rological symptoms occur. The straight leg raising test does not cause pain in the lumbar spine.

Lumbago. a. Acute: Pain occurs on palpation of the back and/or gluteal region. There is increased muscular tension in the lumbar muscles, and a definite loss of motion. Pain occurs when the back is moved. No neurological findings are seen. The straight leg raising test is positive. Straining, coughing, sneezing, and similar activities usually increase the pain in the back.

b. Chronic: Occasional pain occurs on palpation of the lumbar spine, and there is often a limitation of motion. There are no neurological findings. The straight leg raising test may be positive.

Sciatica. a. Sciatica: Pain on palpation may be present in the lumbar region and/or in the leg. There is no increased tension of the lumbar musculature. Movement is limited in the lumbar spine, and also sometimes in the hip joint. The straight leg raising test is positive. Neurological findings may be present.

b. Rhizopathy: Clinical findings occur as for sciatica or lumbago sciatica. The straight leg raising test is positive. Neurological findings are present. Straining, coughing, sneezing, and similar activities give rise to pain in the engaged radicular segment.

Lumbago sciatica. Clinical findings are the same as for lumbago and sciatica. Either of the two can be dominant.

\section{Parenthetical information}

Radiographic diagnosis

Trauma

Psychiatric, psychological or social diagnosis

Pathoanatomically defined diseases of the back (eg, spondylitis, tumors)

Received for publication: 16 March 1982 